\title{
Developments in Lower Limb Exoskeletons For Rehabilitation Application
}

\author{
Bvnr Siva Kumar, Raghavendra Sharma, D Sreenivasa Rao
}

\begin{abstract}
As per the Census 2011, In India, 2.68 Crore people are disabled out of 121 crore population. Of these, $20 \%$ of the people are suffering with disability in movement. Exoskeletons are for Augmenting, Assisting and Rehabilitating the needy people. Exoskeletons are mainly classified into Human augmentation, Assistive and Rehabilitation. Rehabilitation exoskeletons are used in Therapeutic training to bring the affected people into their normal life. In stroke patients and SCI affected people, normal walking becomes difficult. For these people, Gait training is given to restore. This could be with either fixed Setup on a Treadmill, preferably in Hospitals and Therapy centers or Mobile devices for personal use. Many devices are developed around the Globe for walking practice. Also, for Hip-knee-ankle- foot movement. Modular designs with Assist-when-needed technology make these models effective. Recently developed models are taken for review. Commercial models available in the market are also presented with their features.
\end{abstract}

Index Terms: Exoskeleton, Lower Limb, Rehabilitation, Electromyogram.

\section{INTRODUCTION}

As per the Census 2011, in India, 2.68 crore people are disabled out of 121 crore population. Of these, $20 \%$ of the people are suffering with disability in movement. Most of the people are in the age group of 20-39, 40-59 and $>60$. In these groups, near to $25 \%$ are with movement difficulty[1]. These people are to be brought into normal life with Rehabilitation and Assistive Technologies. With Exoskeletons, this dream comes to reality by reducing dependence and making them to live independently without further health disorders. If Lower limb movement is affected, then movement disorders result. Thus lower Limb Exoskeletons give the solution for different disabilities.

In this review, the features of Exoskeletons developed for Rehabilitation are discussed. New devices appear from different parts of the globe. This review could give us an overview of these developments in a brief way. The robotic exoskeletons could be divided into three broad categories based on their application. First one is "human performance augmentation exoskeletons" for expanding physical abilities of Healthy people. These could be utilized for lifting

Revised Manuscript Received on October 30, 2019.

* Correspondence Author

Bvnr Siva Kumar* ,Department of ECE, Laki Reddy Bali Reddy College of Engineering, Mylavaram, A.P -521230, India.

Raghavendra Sharma, Department of ECE,Amity University Madhya Pradesh, Maharajpura Dang, Gwalior M.P-474005, India.

D. Sreenivasa Rao, Department of ECE, JNTUH College of Engineering, Kukatpally, Hyderabad T.S.-500085, India.

(C) The Authors. Published by Blue Eyes Intelligence Engineering and Sciences Publication (BEIESP). This is an open access article under the CC BY-NC-ND license (http://creativecommons.org/licenses/by-nc-nd/4.0/) substantial articles, conveying overwhelming burdens over long separations, or working with Tools like Heavy drilling Machine at a height. These are utilized in stockrooms, building destinations, crisis alleviation tasks, or army installations

The second one is "Assistive devices for individuals with disabilities”. Disorders like Neural Stroke, spinal cord injury, muscle weakness, and Post operative Patients would face difficulty in walking or moving the arm. As per the Survey in 2011, India has a population of with difficulty in movement. These devices could bring people into normal life. A person affected with lower limb paralysis could walk on his own by wearing this device.

The third one is "Rehabilitation exoskeletons for restoration". These gadgets can help, oppose, or irritate the client's movements to accomplish remedial exercise. They can prepare a person's muscles as well as sensory system to enable them to beat the limitations of an inability, when they are not utilizing the exo skeleton. ease of use[2].

Assessing the progress becomes very difficult due to the fast developments in technology and the availability of scientific publications in the field. For devices that are focused on solely assisting able bodied individuals with locomotion, metabolic cost is clearly the most accepted standard. As designs, hardware, and control systems improve, the hope is that more robotic exoskeletons will actually provide an energetic benefit to the userfor walking and running. Fatigue, productivity, and safety are the parameters to evaluate Assistive exoskeletons. Also, EMG analysis is used to monitor the variations and estimate the progress in the patient. Wheelchair bound patients face other complications due to movement less position. Exoskeletons for rehabilitation are aimed to be used in clinical environments.

\section{EXOSKELETON MODELS - WORKING}

In post stroke condition, normal gait deficits observed in lower-limb-affected people include a combination of weakened muscle strength, coordination and excessive muscle tone in the paretic limb. Due to these, knee function is instable in flexion or hyperextension, and foot clearance would be less on the paretic side during the swing phase of gait[3].

Post-stroke gait training primarily focuses on improving load acceptance on the paretic leg during stance. This results in larger stride length. During swing, Foot clearance would be increased due to increase in hip and knee flexion of the affected leg.Training for stroke patients corresponds to only one leg. Thus, the healthy leg motion is monitored, and path is analyzed. The same is applied in the process of training the effected leg. But, for SCI patients, both sides would be paralyzed. Thus the training involves both the legs [4].

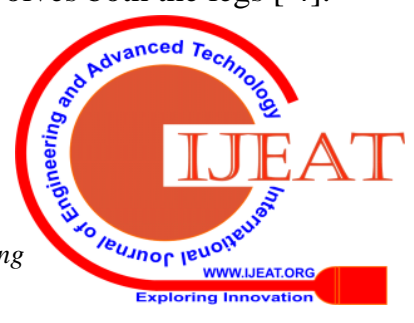




\section{Developments in Lower Limb Exoskeletons For Rehabilitation Application}

The Devices developed for GAIT training could be classified in two ways. In case of acute disorders, the first phase of training is given by fixed Lower Limb models. These include a Treadmill or a similar structure. Assisted treadmill training is available either manually or robotically. In this therapy, a portion of the patient's body weight is suspended above a treadmill through an overhead suspension point. In manual mode, one or more therapists change the patient's pelvis and limbs as needed. In Robotic version, manipulation of the legs is by robotic control. Thus having consistent interaction with the patient.

LOKOMATFig. 1(a) from HOCOMA is the first generation Device designed for Rehabilitation, based on treadmill.It consists of a support system for the body and lower limb attachments. Hip and knee joints are actuated by motor drives. Force sensors are placed to measure the torques at joints. Measured signals are used for monitoring the effect of training. It was added with an adaptive controller to provide the required torque based on the user initiative. Further models include Graphical user interface for the use of physiotherapist during training. This device was proved as an Automatic gait trainer [4].

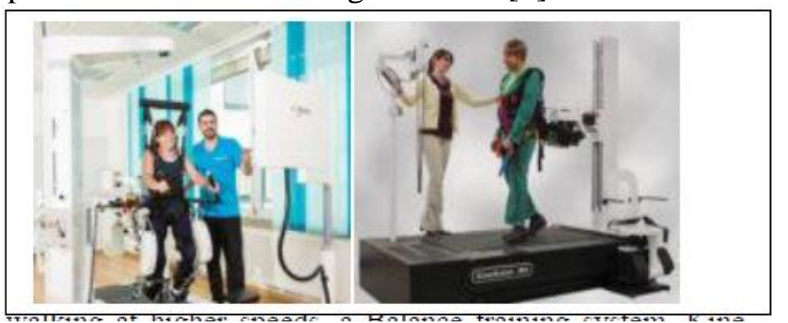

While the Treadmill is used to train post stroke patients with walking at higher speeds, a Balance training system, Kine - AssistFig. 1(b). was designed [5]. The patient is pushed to walk at further speed. When the person tends to fall due to slip, tumble, the pelvis height is monitored. When it crosses a threshold, a harness system will catch hold of the person and forward movement will be stopped by halting the belt mechanism. Thus the patient is stopped from fall and even from its feel. They could feel safe. This gives the confidence of walking at higher speeds and to check the maximum limit.

Another treadmill based RheoAmbulatorFig.2(a). was developed by Motorika, USA. It works with Virtual Reality and closed loop feedback. As per the needs of the patient, a Specific program could be applied by a selected or modified version. During the Training, various parameters are monitored and given as feedback. Base on these the real time audio will be presented. The Visuals reflect the changes observed. With this continuous monitoring and feedback, the person would understand the effects and the Training is more effective. Thus the training cycles are reduced[6].

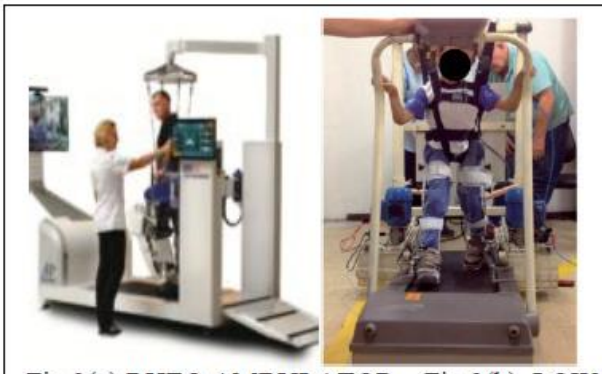

Fig.2(a).RHEO AMBULATOR Fig.2(b). LOW COST

A lowcost Rehabilitation exoskeleton at an estimated price of 25,000 EUROsFig.2(b) was developed in Federal University of Minas Gerais, Brazil and ETH Zurich, Switzerland [7]. In Children with Neurological disorders, the walking ability could be restored with this model. The developed model is intended for Robotic assisted gait training for $\mathrm{CP}$ patients as well in Clinical practice.This model could be attached to a Tread-mill and be synchronized with its operation. The hip-knee-ankle-foot attachment is connected to the patient. The ankle driving system is driven by $0.33 \mathrm{kw}$ motors, PLCs and PID control. To cater for range of people, Body weight support system is included.To control the ankle's movement, the guidance unitconsists of a cam system, a chain to pull, a motor, a sprocket for chain movement, and sensors to indicate the start and stop points in the gait phases.

HOISTFig.3(a)exoskeleton was developed for the use in rehabilitation of walking after injuries or neural disorders. A multi-step process is needed to restore the walking. The device is built on a stable chassis with four free wheels and another two motor driven wheels. Abattery, Control circuits and two $100 \mathrm{~W}$ geared motors are on the unit. A support rods are interfaced with a ball joint and adjustable coaxial springs. This balancing mechanism would limit the user movement due to the limited degree of freedom, they have. The user would be prevented from a fall. HOIST is to observe the patient and adapt the control to maintain the neutral position. For this purpose, user position is determined with tilt sensors and pelvis rotation is taken as intention to take a turn. This becomes the fail safe approach as the user is stopped from falling[ 8].

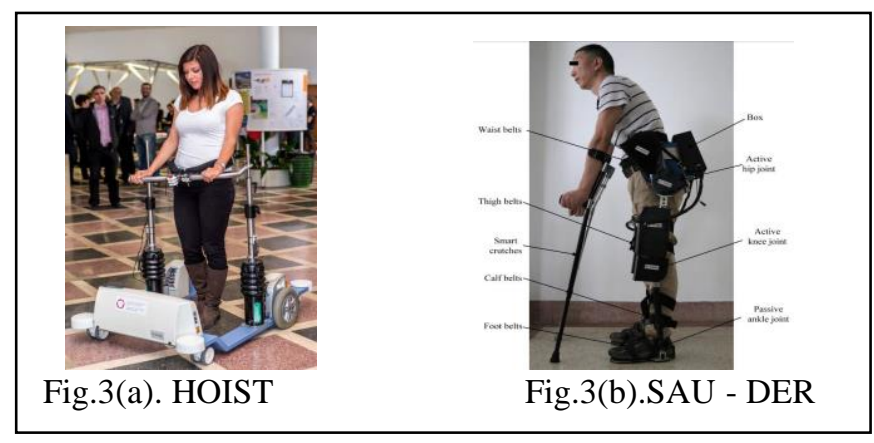

A lower limb exo-skeleton, SAU-DER Fig.3(b). was developed to assist the paralysed individuals in regaining the ability of walking with an independent, functional and reciprocating gait [9]. Also the standing up function could be performed, all with the help of two crutches. The device is designed with special materials to reduce weight and improve comfort. It has total 10 DOF for two legs, of which the hip and knee joints with one DOF each as active and ankle joint with 3 DOF as passive. The total weight is optimised to $21 \mathrm{kgs}$ including Batteries. It is attached to the user with 14 belts including two waist, four thigh, four calf and four feet belts. For the recovery of walking in the persons affected with lower extremity hemi paresis after stroke, an exoskeletonFig4(a) was developed at Vanderbuilt University[10]. This employs an assistive controller that works with active and passive controls. It fully depends on the user initiation and further to assist when required in a step. 


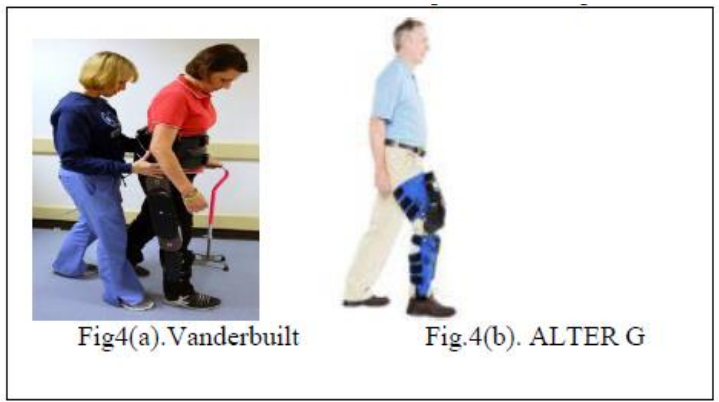

This assistive control resulted in fast recovery as the patient is involved in movement co-ordination. Thus, the patient is involved in every step. At Vanderbuilt University, these developments continue to produce models for multiple applications

Alter G Bionic legFig.4(b) was a proven Lower Limb Exoskeleton. It is of a single joint control and an unilateral device. As a self contained device, it could be directly mounted on the effected knee with both the parts on either side. This is mainly intended for stroke patients with single leg affected. With its powered joint, it strengthens the knee. But, its large size and weight are termed as limitations [11].

For augmentation of human performance as well as for rehabilitation of musculoskeletal system, a lower limb exo-skeleton KIT-EXO-1was developed [12]. Series elastic actuators are used as driving devices instead of motors. It is a 3 DOF design. Interaction forcebetween the exoskeleton and the human body itself is usedfor controlling the actuators. Based on this force and spring deflection, progressive helical springs change the stiffness and work along with Series Actuators.

IndegoFig.5(a). is a modular exoskeleton with five modules. a hip segment, an upperand lower leg segments for both right and left legs. These could be easily assembled and removed, also could be stored. The Battery pack is placed in the hip attachment. Hip and knee joints are driven by brush less DC motors placed in the thigh attachment. Knee joints are fitted with locked brakes. In case of power failure, this locking would save from the instability of the knee. This exoskeleton weighs around $12 \mathrm{Kg}$, including battery. It could be seen as self contained as no back pack is required[13].

A prototype of simple, light weight and low cost lower limb exoskeleton NODP - HMI Fig.5(b).for children is developed at Ibn To-fail University, Morocco[14]. This is intended for paraplegic children in poor countries. With an Atmega based design, it consists of Brushless motors and Gear boxes with bewel gears. Potentiometers are used for angle measurement, Ultrasonic sensors are used to measure user intention and Force sensors are used to find the foot movement. It was developed in 100 \$ range.

Exoskeletons available in the market for rehabilitation are summarized in the following Tables 1 and 2 [15].
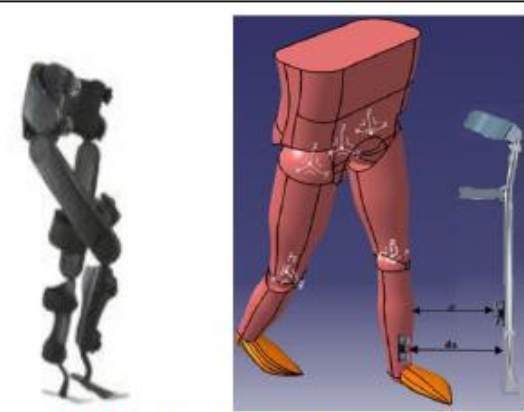

Fig.5(a). INDEGOFig.5(b).NODP-HMI 


\section{Developments in Lower Limb Exoskeletons For Rehabilitation Application}

Table I. FIXED REHABILITATION LLEs

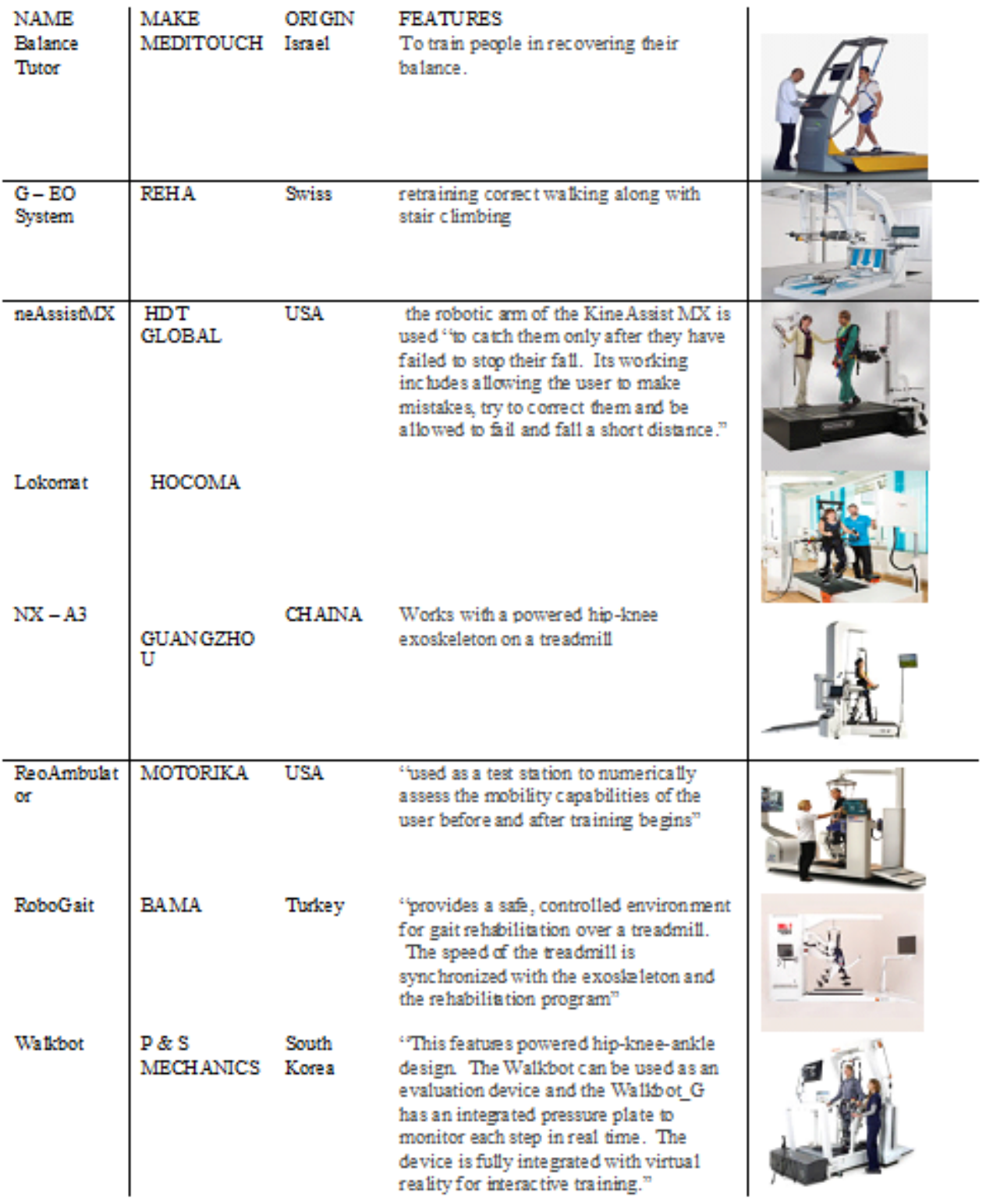

Table. II Mobile Exoskeletons

\begin{tabular}{|l|l|l|l|l|}
\hline ARKE & $\begin{array}{l}\text { BIONIC } \\
\text { LABS }\end{array}$ & USA & $\begin{array}{l}\text { "empower paraplegics and other wheelchair-bound } \\
\text { individuals to walk and rehabilitate. designed to utilize } \\
\text { machine learning and analytics to improve } \\
\text { neurological rehabilitation" }\end{array}$ \\
\hline $\begin{array}{l}\text { ATAL } \\
\text { ANTE }\end{array}$ & $\begin{array}{l}\text { WANDE } \\
\text { RCRAF } \\
\text { T }\end{array}$ & $\begin{array}{l}\text { FRANC } \\
\text { E }\end{array}$ & $\begin{array}{l}\text { "envisioned to be a completely autonomous lower } \\
\text { body exoskeleton that simulates natural movement } \\
\text { and requires no additional balancing aids" }\end{array}$ & \\
\hline
\end{tabular}


Developments in Lower limb exoskeletons for Rehabilitation application

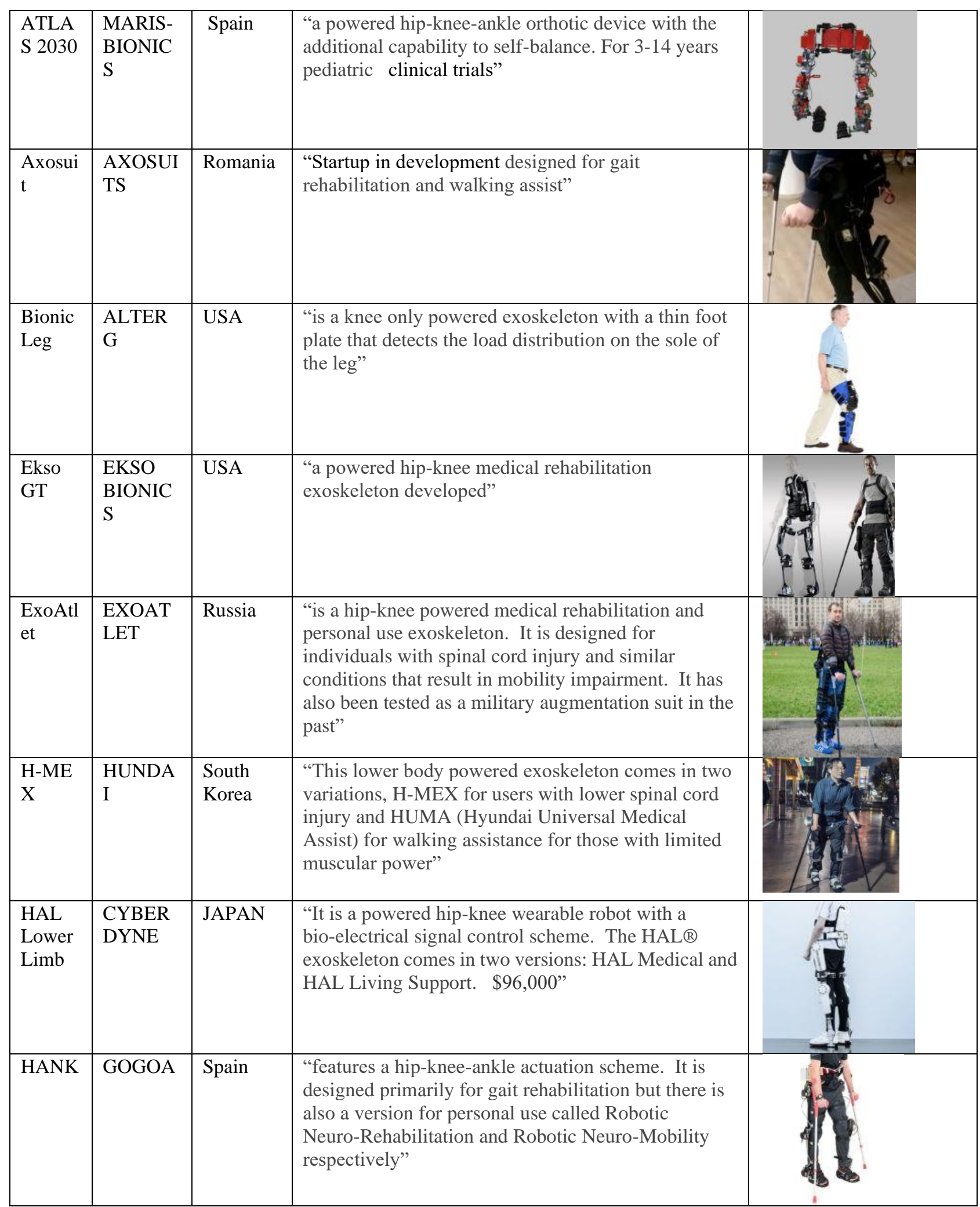




\begin{tabular}{|c|c|c|c|}
\hline Indego & INDEGO & USA & $\begin{array}{l}\text { "The Indego }{ }^{\circledR} \text { can be used for therapy as a gait } \\
\text { training tool. The Indego Personal can also be } \\
\text { employed as a supplementary mobility aid to a } \\
\text { wheelchair. In addition to being able to see people } \\
\text { eye-to-eye, research using this and other assistive } \\
\text { medical exoskeletons has shown a strong correlation } \\
\text { between standing up and a multitude of secondary } \\
\text { benefits. These positive effects include but are not } \\
\text { limited to improved bowel control, increased bone } \\
\text { density and reduction in pressure sores" }\end{array}$ \\
\hline $\begin{array}{l}\text { Phoeni } \\
\mathrm{x}\end{array}$ & SUITX & USA & $\begin{array}{l}\text { "powered hip exoskeleton designed to assist people } \\
\text { with mobility impairments. The PhoeniX sports a } \\
\text { lightweight design, further simplified by having } \\
\text { actuation only at the hips. This brings the cost and } \\
\text { weight down. The exoskeleton knee component locks } \\
\text { in place while standing or bearing weight and unlocks } \\
\text { during the leg swing phase.The exoskeleton is also } \\
\text { compatible with traditional orthotic devices. You can } \\
\text { use your own orthotic and just add actuation at the } \\
\text { hips. As a tradeoff, the PhoeniX is not capable of } \\
\text { providing full assistance while climbing stairs." }\end{array}$ \\
\hline $\begin{array}{l}\text { ReWal } \\
\mathrm{k}\end{array}$ & $\begin{array}{l}\text { REWAL } \\
\text { K }\end{array}$ & ISRAEL & $\begin{array}{l}\text { "Approved by the FDA for clinical and home use for } \\
\text { individuals with spinal cord injury" }\end{array}$ \\
\hline REX & $\begin{array}{l}\text { REX } \\
\text { BIONIC } \\
\text { S }\end{array}$ & $\begin{array}{l}\text { NEWZE } \\
\text { ALAND }\end{array}$ & $\begin{array}{l}\text { "There are two types of the REX exoskeleton: REX } \\
\text { for Clinical Use and REX P for Personal Use" }\end{array}$ \\
\hline ROKI & $\begin{array}{l}\text { ROKI } \\
\text { ROBOTI } \\
\text { CS }\end{array}$ & $\begin{array}{l}\text { MEXIC } \\
\mathrm{O}\end{array}$ & $\begin{array}{l}\text { "This is a modular, powered lower body rehabilitation } \\
\text { hip-knee exoskeleton. It is designed by a start-up } \\
\text { company in Mexico in association with a multitude of } \\
\text { local academic and business groups. In 2016, the Roki } \\
\text { exoskeleton could only be rented within Mexico." }\end{array}$ \\
\hline
\end{tabular}

\section{CONCLUSION}

This review gives the brief details of Rehabilitation exoskeletons developed around the globe. Cost of the Exoskeleton is the limitation for the people in many countries. Custom built devices for a specific application and range would always cost less in comparison to the ones with multiple applications and wide range. Configuring the device becomes simple and it could be optimised in every aspect. As these exoskeletons bring the people back into their normal life at a faster pace at a minimum cost and effort, these should be considered as essential rather than additional by Government Agencies. Utilisation should increase with increase in commercial models and vice-versa. As many exoskeletons are developed in Universities with Industrial participation, Governments should take initiative to encourage and see that the exoskeletons should be made available for the local needy people.

In terms of Technology, fixed and mobile exoskeletons differ. Mobile devices should be compact, modular, Weightless and user friendly. Also, Assist - when - needed technology is found to be beneficial. With composite materials, Strength could be retained at lesser weight and price. APP based usage adds more benefits, such as remote monitoring and control. Fixed devices are for Hospital / Therapy centres, where as the mobile devices could be for personal use. The development of these exoskeletons require Mechanical frames, Electrical/ Mechanical actuators, Electronic sensors with controlling hardware and controlling Software even to monitor. More funds are to be pumped into this field to see that needy people use exoskeletons for Rehabilitation in the near future. Along with Developed countries, this should come to reality, even in developing countries.

\section{REFERENCES}

1. Disabled persons in India - A statistical profile 2016 , http://www.mospi.gov.in

2. Aaron J. Young and Daniel P. Ferris (2017). State of the Art and Future Directions for Lower Limb Robotic Exoskeletons, IEEE Transactions on Neural Systems and Rehabilitation Engineering, 25-3 : 171-182

3. Bing Chen, Hao Ma, Lai-Yin Qin, Fei Gao, Kai-Ming Chan,Sheung-Wai Law, Ling Qin, Wei-Hsin Liao (2015), Recent developments and challenges of lower extremity exoskeletons, Journal of Orthopaedic Translation, 5, 26-37.

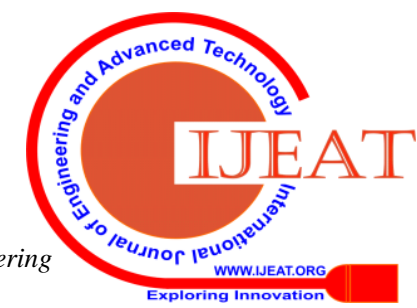




\section{Developments in Lower limb exoskeletons for Rehabilitation application}

4. JezernikS, Pfister Andres, Frueh H, Colombo Gery and Morari, M. (2002). Robotic orthosis Lokomat: its use in the rehabilitation of locomotion and in the development of the biology-based neural controller.

5. Capo-Lugoet. al.(2012), Maximum walking speeds obtained using treadmill and over ground robot system in persons with post-stroke hemiplegia, Journal of Neuro Engineering and Rehabilitation, 9:80.

6. www.motorika.com/REOAMBULATOR

7. Mariana Volpini, Volker Bartenbach, Marcos Pinotti and Robert Riener (2017), Clinical evaluation of a low-cost robot for use in physiotherapy and gait training, Journal of Rehabilitation and Assistive Technologies Engineering, Volume 4: 1-11

8. Matevz Bosnak and Igor Skrjanc (2017), Embedded Control System for Smart Walking Assistance Device, IEEE Transactions on Neural Systems and Rehabilitation Engineering, Vol. 25, No. 3.

9. Z. Zhu, C. Jiang, X. Wang, J. Chen, L. He and Q. Wu (2016), Design of a wearable lower limb exoskeleton for paralyzed individuals, 23rdInternational Conference on Mechatronics and Machine Vision in Practice (M2VIP), Nanjing, pp. 1-6.

10. Spencer A Murray, Kevin H Ha, Clare Hartigan and Michael Goldfarb (2015), An assistive control approach for a lower-limb exoskeleton to facilitate recovery of walking following stroke, IEEE Transactions on Neural Systems and Rehabilitation Engineering, Volume23, Issue3, 441-449.

11. Clare Hartigan, Casey Kandilakis, Skyler Dalley, Mike Clausen, Edgar Wilson, Scott Morrison, Steven Etheridge and Ryan Farris (2015), Mobility Outcomes Following Five Training Sessions with a Powered Exoskeleton Clare, Topics in Spinal Cord Injury Rehabilitation/Spring, ;21(2):93-99.

12. Jonas Beil, Gernot Perner and Tamim Asfour (2015), Design and control of the Lower limb Exoskeleton KIT-EXO-1, IEEE International Conference on Rehabilitation Robotics, N T University, Singapore.

13. Barnak Mukherjee, S. K. Dey and B. B. Pradhan(2018), The recent trends and inspections about powered exoskeletons, IOP Conference Series: Materials Science and Engineering.

14. Elouarzi Abdelkarim, Sedra Moulay Brahim (2019), Development and control of a low cost Exoskeleton system with an interactive HMI designed for paraplegic children, International Journal of Scientific \& Engineering Research, Volume 10, Issue 1, January -2019.

15. https://exoskeletonreport.com/product-category/exoskeleton-catalog/ medical/

\section{AUTHORS PROFILE}

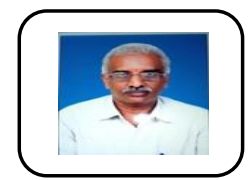

BVNR Siva Kumar received the BTech Degree from K L College of Engg. and MTech from JNTUCE, Kakinada. He is currently working toward the $\mathrm{PhD}$ degree with Amity University Madhya Pradesh. Gwalior. He had worked in Industry for 10 years and in Teaching from past 22 years. At present, he is working as an Associate Professor of Electronics and Communication Engineering Department at Laki Reddy Bali Reddy College of Engineering, Mylavaram, Andhra Pradesh. His current research interests include the modeling of Robotic systems and Human assisting devices.

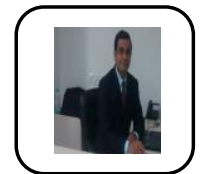

Dr Raghavendra Sharma completed his B.Tech in Electrical Engineering from Dayalbagh Educational Institute Agra, M. Tech in Electronic Design \& Technology from Central Government Institute CEDTI Aurangabad (MS) and PhD from Dayalbagh Educational Institute Agra under the supervision of Prof. V Prem Pyara, Ex. Dean and Director, Dayalbagh Educational Institute Agra in the area of Signal Processing.In his teaching and research career of more than 19 years he has published more than 50 research papers in various Journals and conferences of international \& National repute and he is editor of Engineering and Technology Journal of Research and Innovation (ISSN: 2581-8678). He has guided many Graduates,Postgraduate \& PhD students and he is editorial board member \&reviewer of many International journals. His research interest lies in Digital Signal Processing, Image Processing, VLSI Design, Antenna Design and Soft Computing. Presently he is working as Professor \& Head (ECE) in Amity University Madhya Pradesh, Gwalior.

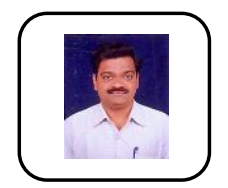

Duggirala Srinivasa Rao received the Ph.D. degree from Central University Hyderabad. He is currently working as a professor of Electronics and Communication Engineering Department at JNTUH College of Engineering, Kukatpally, Hyderabad, Telangana, India. He handled the research projects like Quality of Service in mobile Ad-hoc networks, funded by UGC from 2012 to
2014. He has more than 70 research papers to his credit. His areas of interests are computer networks, wireless networks, and communications. 